Sharif University of Technology
Scientia Iranica
Transactions E: Industrial Engineering
IRANtp://scientiairanica.sharif.edu

\title{
A knowledge-based algorithm for supply chain conflict detection based on OTSM-TRIZ problem flow network approach
}

\author{
J. Razmi ${ }^{\mathrm{a}}$, D. Haghighi ${ }^{\mathrm{b}}$, and R. Babazadeh ${ }^{\mathrm{c}, *}$ \\ a. School of Industrial Engineering, College of Engineering, University of Tehran, Tehran, Iran. \\ b. Young Researchers and Elite Club, Majlesi Branch, Islamic Azad University, Isfahan, Iran. \\ c. Faculty of Engineering, Urmia University, Urmia, West Azerbaijan Province, Iran.
}

Received 27 November 2016; received in revised form 2 August 2017; accepted 23 December 2017

\author{
KEYWORDS \\ Supply chain conflicts; \\ OTSM-TRIZ; \\ Problems flow \\ network; \\ Problems network; \\ Semantic \\ relationships; \\ Conflicts network.
}

\begin{abstract}
The coordination and integration of efforts and activities of Supply Chain (SC) members, which is a key component in the success of the supply chain management, has become a challenging issue due to conflicts in such systems. Inability to properly detect conflicts in an SC and, therefore, mismanagement of them will increase disruption risk in the SC. In this article, a knowledge-based algorithm is presented based on the OTSMTRIZ (general theory of powerful thinking) problem flow network approach to identify, formulate, and solve the conflicts of SCs before they occur and cause harmful effects. The proposed algorithm involves analyzing and developing Network of Problems (NoPs) in order to transfer them into a network of conflicts. The algorithm is validated through presenting a case study. After implementation and application, the result demonstrated that this knowledge-based algorithm was able to identify and formulate supply chain conflicts before they occurred and, more importantly, it greatly increased the coordination between supply chain entities.

(C) 2018 Sharif University of Technology. All rights reserved.
\end{abstract}

\section{Introduction}

Successful management of supply chain requires the integration of mutual functions. Therefore, the major task in supply chain management is accurate and timely collection of customers' demand and delivering the right product with the right quality at the right time and the right location [1]. One of the most challenging problems in supply chain management is the conflicts that may occur between supply chain

\footnotetext{
*. Corresponding author. Tel.: +984412972854;

Fax: +984412773591

E-mail addresses: jrazmi@ut.ac.ir (J.Razmi);

Haghighid@ut.ac.ir (D.Haghighi); r.babazadeh@urmia.ac.ir (R. Babazadeh).
}

doi: $10.24200 /$ sci. 2017.20021 entities or inside each of them $[2,3]$. Conflicts in an SC can be a result of mutuality of objectives of different entities, incompatibility of tasks, inefficiency of working scope definition, mutuality of operations scheduling for different entities (supply, production, and distribution), mutuality of key performance indicators of each entity with those of other supply chain entities, and mutuality within each of the entities to achieve the ultimate goals of the entire supply chain [4]. An example would be conflicts that often exist between service level and product quality such that in some cases, the unavailability of goods and lack of timely delivery by well-known suppliers propels the managers to the use of domestic and local suppliers [5]. While purchasing from domestic suppliers improves timely delivery and service level, incapability of local suppliers in providing products with high quality will reduce 
quality of the final products [6]. Therefore, effective management of conflicts in order to reduce detrimental effects of them and enhance the competitive condition of supply chain is very necessary.

The intent of this paper is to address conflicting issues and present a structured approach to managing supply chain conflicts. Specifically, the paper intends to present a systematic algorithm through the development of a knowledge based algorithm based on OTSMTRIZ approach for managing complex interdisciplinary problems. The research activity has been organized following a five-step algorithm for managing supply chain conflicts. In the initial steps, efforts have been put into analyzing the current situation of supply chain in detail, which seeks to generally identify all related problems, with $3-\mathrm{D}$ system operator. In the next steps, a problem flow network has been used to make a systematical structure of all related problems and conflicts as a semantic network. The research activity has been carried out in collaboration with a manufacturer of commercial vehicles in Iran. In this paper, due to critical importance of correct identification and formulation of supply chain conflicts, the first three steps of the above-mentioned algorithm are presented, and resolution and evaluation of the results are to be carried out in future studies.

The body of this paper is organized as follows: In Section 2, initially, we discuss the importance of supply chain conflict detection and the diversity of conflict detection methodologies that have been applied to a wide variety of problems. Then, in Section 3 , since our proposed algorithm for conflict detection is based upon the concept of OTSM-TRIZ problem flow network, we briefly discuss the problem flow network of general theory of powerful thinking. We present the knowledge-based algorithm in Section 4 and provide a case study that supports the algorithm in Section 5 . Section 6 concludes the paper and offers some future research directions.

\section{The effects of disruptions caused by supply chain contradictions}

Conflict is a serious problem in supply chain systems and results from issues such as payment, poor communications, natural disasters, etc. [7]. It can have negative effects on supply chain performance and cause problems like increasing the cost of supply chain, delay, productivity reduction, loss of profit, and damage to business relationships [5]. There are some studies that examine the amazing impact of supply chain conflicts. For instance, Rice and Caniato [8] studied the performance of a company and estimated a $\$ 50$ million to $\$ 100$ million cost impact for each day the supply system was interrupted. According to the study of Brockman [9], the approximate annual cost of supply chain conflicts is about $\$ 5$ billion. Pyke and Tang [10] pointed out $\$ 500$ million loss of Intel company, due to conflicts in integrated design of Pentium microprocessors, which led to recall of 5.3 million chips in 2004. The recent work by Hendricks and Singhal [11] showed that these disruptions could affect shareholder wealth and supply chain operational performance. According to the reports of Hendricks and Singhal [12-14], publicly announced disruptions have shown the decrease in shareholders by $10 \%$ in short term and $40 \%$ in long term. Also, disruptions in publicly traded firms are found, on average, to be associated with a $107 \%$ fall in operating income, a $114 \%$ fall in return on sales, and a $93 \%$ fall in return on assets. Although the need for supply chain identification is noted in previous studies, an innovative approach to identifying and formulating conflicts in a systematic way is needed. Hence, the need for a knowledge-based and systematic algorithm for identifying and formulating conflicts of the supply chain is felt more than ever. In the next subsection, a number of methods used to identify conflicts in other fields and supply chain systems are discussed.

\subsection{The proposed methodologies for identifying the conflicts}

Identifying and resolving the conflicts in various fields have been taken into consideration. In the field of developing new products, Lam and Chin [15] examined critical success factor in identifying and management of conflicts in collaborative New Product Management (NPM). Felty and Namjoshi [16] suggested a methodology to identify conflicting features in specification stages of product design process.

In project management, Mitkus and Mitkus [17] offered a communicational approach to identifying the main causes of conflicts in construction projects. Acharya et al. [18] presented an AHP tool to find the major construction conflicting factors and responsible parties for those problems.

In supply chain management, Hsieh et al. [19] presented a methodology for analyzing distribution operation in a supply chain as an integrated system in order to identify potential conflicts of supply chain systems. Their approach was based on linking hierarchical levels of the supply chain system and detecting conflicts occurring when the single entities, each optimized for its own operations, were combined together. John and Prasad [20] presented a methodology for identification of supply chain conflicts with colored petri net. They tried to provide the users with the ability to search the potential for conflicts in the distributed channels and find them as soon as possible after they occurred. He et al. [21] presented a hierarchical approach to study supply chain conflicts between Airbus and Boeing. He et al. [22] developed a hierarchical graph model of a two-level carbon emission conflict in China. Some 
important issues all the mentioned methods have not paid attention to are the following:

- Lack of an approach to detection of conflicts in a system (identification of the root of conflicts);

- Lack of attention to the semantic relationship between conflicts-the network relationships between conflicts (the previous research has not considered conflicts separately);

- Lack of a clear strategy to resolve the conflicts.

The mutual interdependence between systems converts separate organizations into a network of cooperative activities connected to each other by a flow of materials, information, knowledge, and resources [19]. Due to rapid growth of information technology and globalization, the complexity of interaction between different inputs of supply chain has also increased in terms of different aspects such as the flow of materials, information, etc. [20]. Therefore, it is difficult to understand and improve such systems. In order to confront these challenges, different tools and models for representing a material flow as well as the flow of information, sources, and system behaviors are required to analyze such systems [23]. What is so important about this issue is the network approach to the flow of resources, information, and materials, which is the common feature in almost all of these methods. Hence, in order to moderate the complexity of the process and interrelationships between flows of information, materials, and energy, the use of networkbased methods is required more than ever.

\section{Problem flow network approach to OTSM-TRIZ}

As stated previously, OTSM (general theory of powerful thinking) is one of the developed versions of TRIZ that was presented by Khomenko et al. [24]. Within the framework of OTSM-TRIZ, a complicated problem can be considered as a network of simple sub-problems, which is known as a network of problem flows. A network of contradictory parameters, representing the network of conflicts, in the background of the network of problems increases the complexity of solving procedure [24].

Problem-solving process becomes difficult when the problem, in addition to being complicated, is related to the fields such as technical, economic, social, and environmental issues [25]. OTSM-TRIZ includes tools and models for management of such networks. Network of problems is a graphical representation in which nodes are indicative of problems, sub-problems, and partial solutions [24]. Micro or partial solutions are tacit or explicit knowledge resulting from the experiences of experts. Such solutions have two features:
1. They solve a problem, but subsequently the problem or other problems are caused;

2. They only resolve one or several sub-problems and do not have the ability to solve the main problem completely [26].

Each of these sub-problems reflects the role of different subjects that are involved in the leading main problem. Each problem should have at least one partial solution and if one sub-problem has no partial solution, it has not been defined correctly, because one of the main ideas of developing the network of problems is breaking down the main problem into subproblems that can be easily solved [27]. The network of problems offers a comprehensive map of the main problem through breaking it into a set of sub-problems and partial solutions. In this network, problems and solutions are shown as nodes and the relationship between them is shown by a vector (see Figure 1). The relationships between these nodes represent the hierarchical structure of a complex problem situation along with several options for solving sub-problems in order to solve the main problem. The strength of NoP presentation is providing the possibility to simultaneously produce and visualize several problem scenarios [25].

The Network of Contradiction (NoC) [28] is a subsequent interpretation of the NoP and integrates information about the contradictions of the nodes of the network, which are constituted by parameters represented by Element-Name-Value (ENV) models [24], i.e., by specifying the Name of the parameter, its Value, and the Element it belongs to. It is possible to distinguish parameters in the following classes:

- Control Parameters (CPs): They can be leveraged by the decision makers in order to obtain a specific outcome;

- Evaluation Parameters (EPs): They describe the positive or negative implications of the choice of the decision makers (network of contradictions analysis and structured identification of critical control parameters).

Figure 1 represents the network structure of conflicts [28].

\section{Proposed knowledge-based supply chain conflict detection algorithm}

As discussed in the previous section, the existing methodologies to find and formulate the supply chain conflicts fail to properly map all the conflicts and relationships between them as a semantic network. The main contribution of this paper includes a procedure to help detecting supply chain conflicts with a knowledgebased logic. 


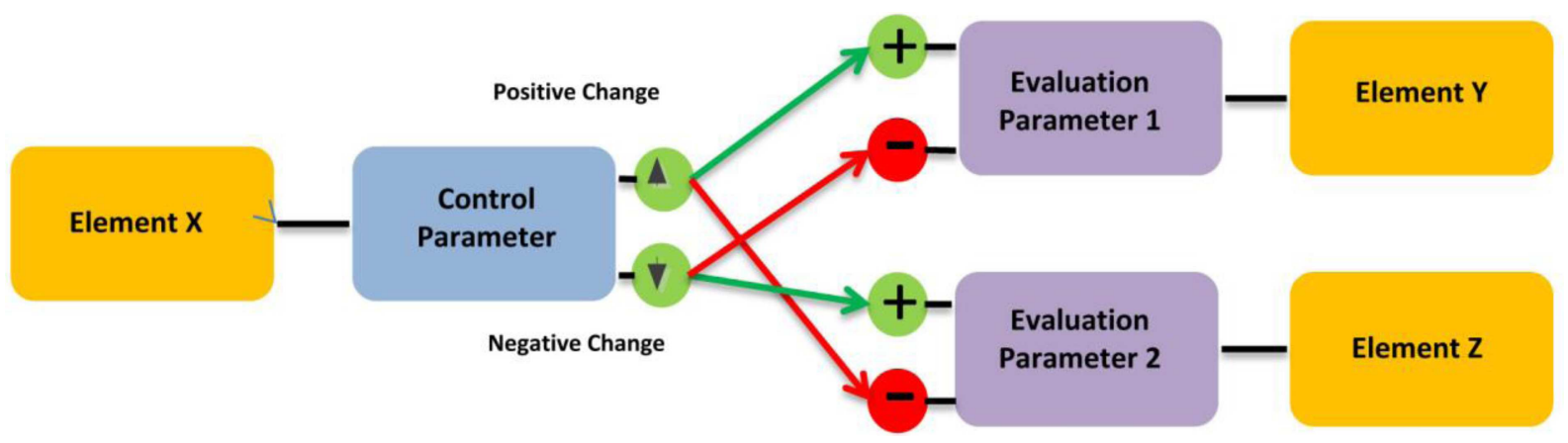

Figure 1. OTSM-TRIZ model of conflict, characterized by one CP and two EPs.

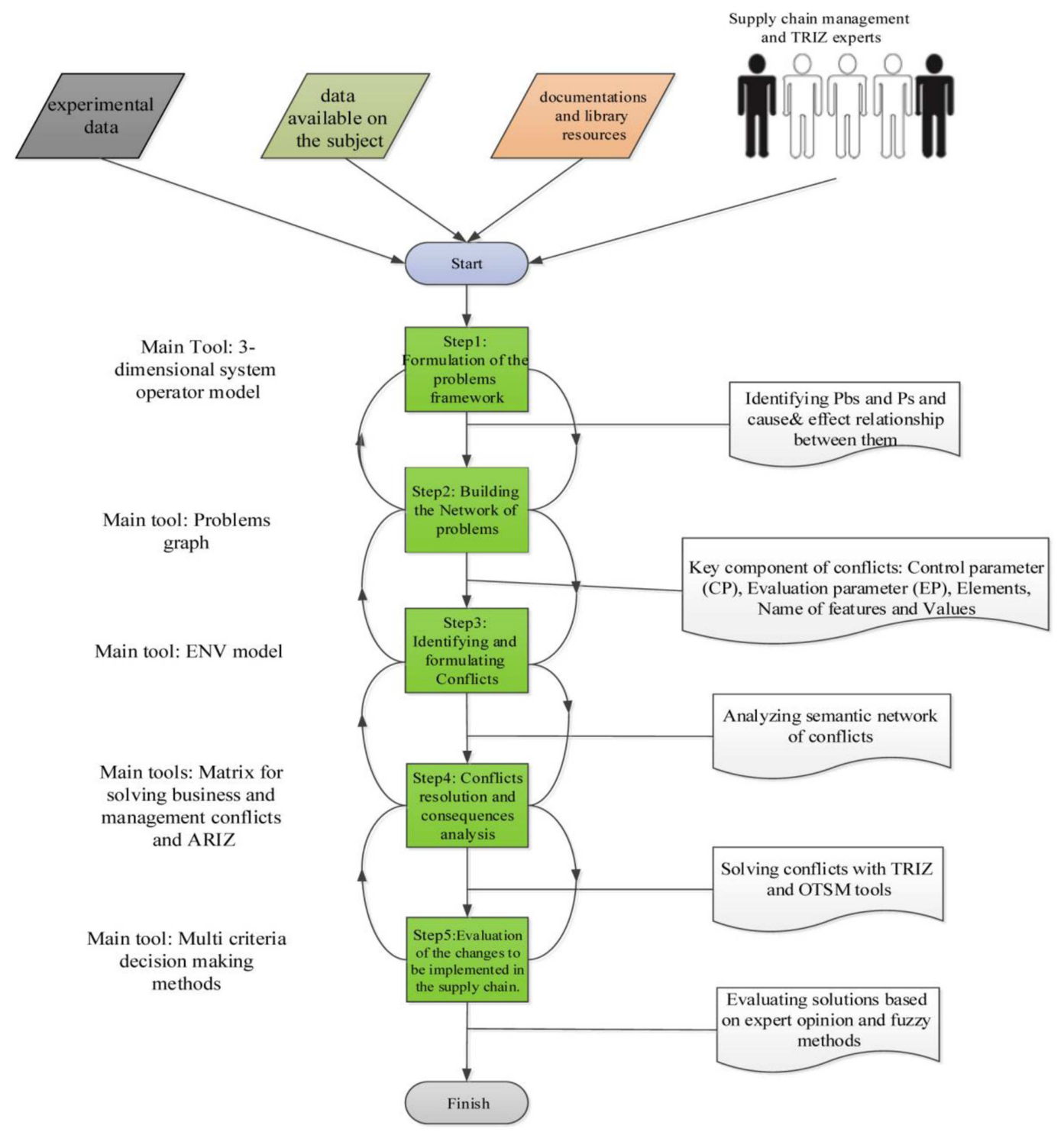

Figure 2. The proposed five-step algorithm for identifying and managing supply chain conflicts.

The 5-step algorithm, which is shown in Figure 2, can be considered as a kind of practical algorithm that describes all the specific actions to do in order to correctly analyze and formulate supply chain problems.

The steps of the proposed algorithm are as follows.
- Step 1: Formulation of the problem's framework. At this stage, an analyst with a focus on the current situation (i.e., As-Is Situation) and its various levels seeks to receive a proper understanding of the problem status. One of the most important tools 


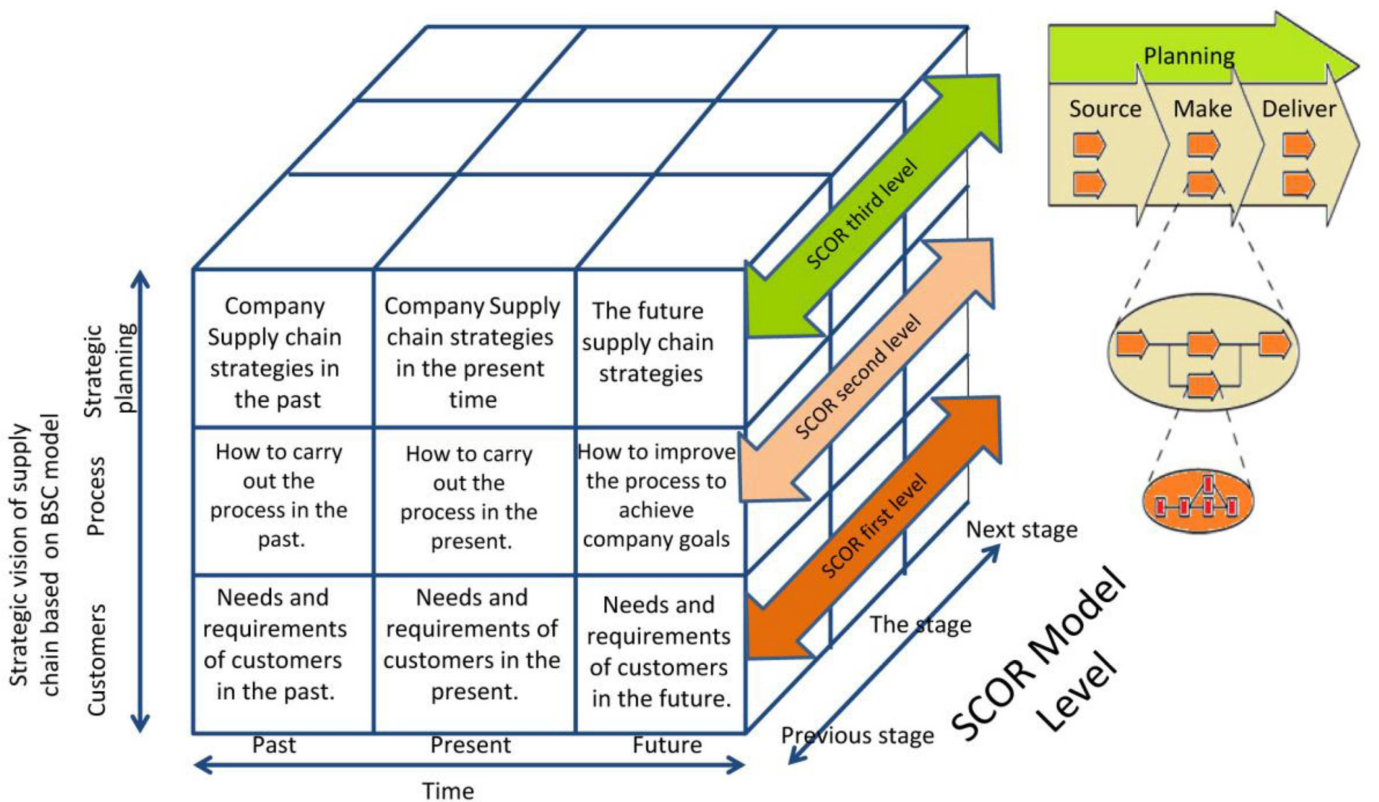

Figure 3. 3-D operator system model for analyzing supply chain problems.

of TRIZ, which can be used at this stage, is twodimensional system operator model [25]. The TRIZ system operator tool is composed of two dimensions of time and system hierarchy. An internal element of the tool shows the evolution of the system at different times, and it is based on the level that the problem is analyzed [29].

In this paper, we present an innovative $3-\mathrm{D}$ operator system, which is shown in Figure 3. This tool is modified to analyze supply chain problems. In the proposed tool, the first dimension is considering the problems in different periods of time and, depending on the level in which we are going to analyze supply chain, the triple levels of Supply Chain Operations Reference model (SCOR) will be used. The third dimension is strategic vision of supply chain management at three different levels of strategic plan, customers, and processes, which is based on Balanced Score Card (BSC) model [30]. The main tasks in this step are as follows:

(a) In the first step, the level of supply chain SCOR model to which the problem is related is determined. If the problem is related to internal processes of one of the supply chain entities, such as production, supply, or distribution, the third level of SCOR model is used. If the problem is related to the processes with two or more supply chain entities, the second level of SCOR model is used; and if the problem is related to the entire supply chain, the first level of SCOR model is used. In the new versions of the SCOR model, if there is a need for more rigorous analysis than the third level, a fourth level is informally added [31]; (b) In the next step, the stage in the SCOR diagram to begin the analysis is chosen. It is the stage to which the main problem is related;

(c) In the final step, 3-D operator system is completed. The axes of this model are:

- Axis X: time (past, present, and future of the supply chain problem and the level in which the problem is being considered);

- Axis Y: levels of supply chain strategic vision based on balanced scorecard model, including strategic plan, customers, and internal processes. Based on the conditions of the problems, some financial, environmental, technologic, and knowledge-related aspects can also be added to them;

- Axis Z: different levels of SCOR model.

The only step of the algorithm that can be time-consuming is collecting problems and partial solutions, and the main criterion to stop this step (making the space of problems and partial solutions) is when no partial solution leads to a new problem.

- Step 2: Building the network of problems. For tackling complex problems, problem solvers often try to decrease the complexity through dividing the problem into sub-problems [25]. In complex problems such as supply chain problems, the main problem may be a sub-problem of a super-problem. By using the PFN (Problem Flow Network) approach, we can represent and analyze several problems at once. The main stages of PFN approach are to build, first, the network of problems, second, the network of parameters and, last, the network of conflicts [28]. 
At this stage, based on the modeling method of problems' graph, first, the sub-problems of the main problem are defined based on its various scenarios. Decomposition of the main problem into related sub-problems is continued to the point that any problem cannot be broken down into more subproblems. Then, one or more partial solutions are defined for each sub-problem [25]. After completion of the network of the problems based on the semantic relationships between the problems and partial solutions, the network of the problem's parameters is defined and then, the network of the conflicts of the problem is drawn.

The steps done in this stage are as follows:

(a) Determining the main problem or making changes in the supply chain based on different levels of SCOR;

(b) Making a list of sub-problems and partial solutions, which are prepared based on different scenarios, and making the logical connection between them to build a network of the problems. In the meantime, the following items must be considered:

(b.1) For each sub-problem, at least one partial solution must be provided;

(b.2) For each partial solution that is provided, in addition to determining the relationship and the impact that it has on other solutions, at least one sub-problem must be provided [25].

Items (b.1) and (b.2) will continue to the extent that the network cannot be wider. The output of this phase is a comprehensive map of the main complex problem, including its sub-problems, the partial solutions, and their semantic relationships.

- Step 3: Building the network of conflicts from the network of problems. After validating the network of problems, we have to extract the specific parameters of the supply chain system with the help of experts or depending on the knowledge gained during the initial analyzing. The elicitation of parameters from the network of problems has to be done as follows:

- Each sub-problem $(\mathrm{Pb})$ is related to one aspect of the main problem that should be satisfied; at least one Evaluation Parameter (EP) can be determined to evaluate the level of consent to such expectancy;

- Each Partial Solution (PS) extracts at least one path to solve a sub-problem; at least one CP can be related to the characteristic used to take into account the related problem [32].

The relationship between control and evaluation parameters can be arranged based on their causeand-effect relationships [25].

After completing the lists of CPs and EPs according the methods described in the previous sections, we should evaluate the potential effect of each CP on each EP; then, it is identified whether a certain change of a $\mathrm{CP}$ causes contradictory effects on two or more EPs. To be more precise, the following step should be done:

- Determining two opposite values for each CP and selecting a reference direction (e.g., from decrease to increase or attribute versus anti-attribute).

After assigning the EPs and CPs to each problem and identifying partial solutions, we can analyze the conflicting relationships between them.

Due to the importance of identifying and formulating supply chain conflicts, our study covers Steps 1 to 3 and Steps 4 and 5 are considered for future research. Briefly, Steps 4 and 5 are as follows.

- Step 4: Resolving conflicts. At this stage, the conflicts which have been formulated in the previous stage are resolved based on the tools and models that have been provided by theory of inventive problem solving. TRIZ, depending on the type of conflicts and their complexity, provides different tools such as 40 principles of innovation and the matrix of conflicts, innovative standards, and an innovative solving algorithm for the problems, which is called ARIZ85C.

- Step 5: Evaluation of the solution. At this step, the solutions to conflicts resolving, which are the output of the previous step, will evaluate and rank each problem they can solve based on its importance by using multi criteria decision making methods.

Consequently, in order to prove the efficiency and effectiveness of the proposed algorithm, this method is used for identifying and formulating conflicts of supply chain problem in a real environment, which is discussed in the next section as a case study.

\section{The knowledge-based algorithm: A case study}

In order to prove efficiency and effectiveness of the proposed algorithm, the algorithm is used for identifying and formulating conflicts of supply chain problem in one of the Iranian automotive manufacturing industries. This manufacturing company is active in the field of mass vehicles (urban, suburban, and middle-class buses). In this factory, three production lines are working in parallel to produce mass vehicles. These production lines were designed based on the common platform strategy. Strategic vision of this factory enhances customer satisfaction through receiving and analyzing customer demands and translating them into functional requirements at different levels of production hierarchy including design, prototype, 
test, manufacturing, and mass production. To achieve this goal, the management have decided to improve the internal and external processes and establish an effective relationship with their suppliers in all phases of production. One of the processes that has made many technical and non-technical problems is coating process. The machineries and equipment of this station are old-fashioned. This station is the main bottleneck of the production line and makes serious problems for coordination and integration of the production processes. Therefore, fulfilling customer orders according to the predetermined schedule is faced with considerable delay. To deal with this problem, the management have decided to renew old apparatus of painting station with semi-automatic equipment. Replacing new equipment with the old equipment needs two months of time and replacing process will lead to stopping production line 3 . To confront this problem, the problem-solving team is formed to review all aspects of the issue, adopt an appropriate strategy to reduce the costs of replacing, and improve the company's strategic position among competitors. The proposed algorithm is used to consider all aspects of the problem and identify the root conflicts that may cause detrimental effects on the supply chain performance.

- Step 1: In this step, for having a comprehensive understanding of the problem's situation, the problem solving team builds a three-dimensional operator system. In this case, as the problem is related to the production line, the third level of SCOR model is adopted to analyze and evaluate the problem.

A simplified view of the company's supply chain SCOR diagram is presented in Figure 4. As shown in the figure, first, the main room structure is built in the building room unit and, then, by using the traditional ways of painting, the room structure is painted. The painted frame enters the chassis assembly station, and chassis assembly process, which includes installation of all systems and subsystems, is done in this step. Next, the product enters the trim station, and the seats and other amenities are assembled. Then, electronic and electrical systems of the vehicle, including all required software and equipment, are installed in the electrical station. Installation of ABS anti-lock braking systems on the front and rear axles of the vehicle is done at this stage. Next, the process needed for completing the product is done in the complementary station.

For having a general picture of the problem constraint, Table 1 shows each of the components of the three-dimensional system operators for the replacing problem. As we mentioned, the production lines have retarded equipment, which decreases the quality and quantity of the production. Thus, improving production line with new equipment is a necessity. In other words, this change is necessary, because according to the vision of the company, they have to "guarantee a sustainable development of public transportation vehicles" and reach "higher levels of public satisfaction".

- Step 2: a complete description of the problem space by establishing a network of problems flow.

(a) The primary problem in this case study is to replace the old equipment and machines of coating station in line 3 with new semi-automatic equipment. This problem is determined as a major one

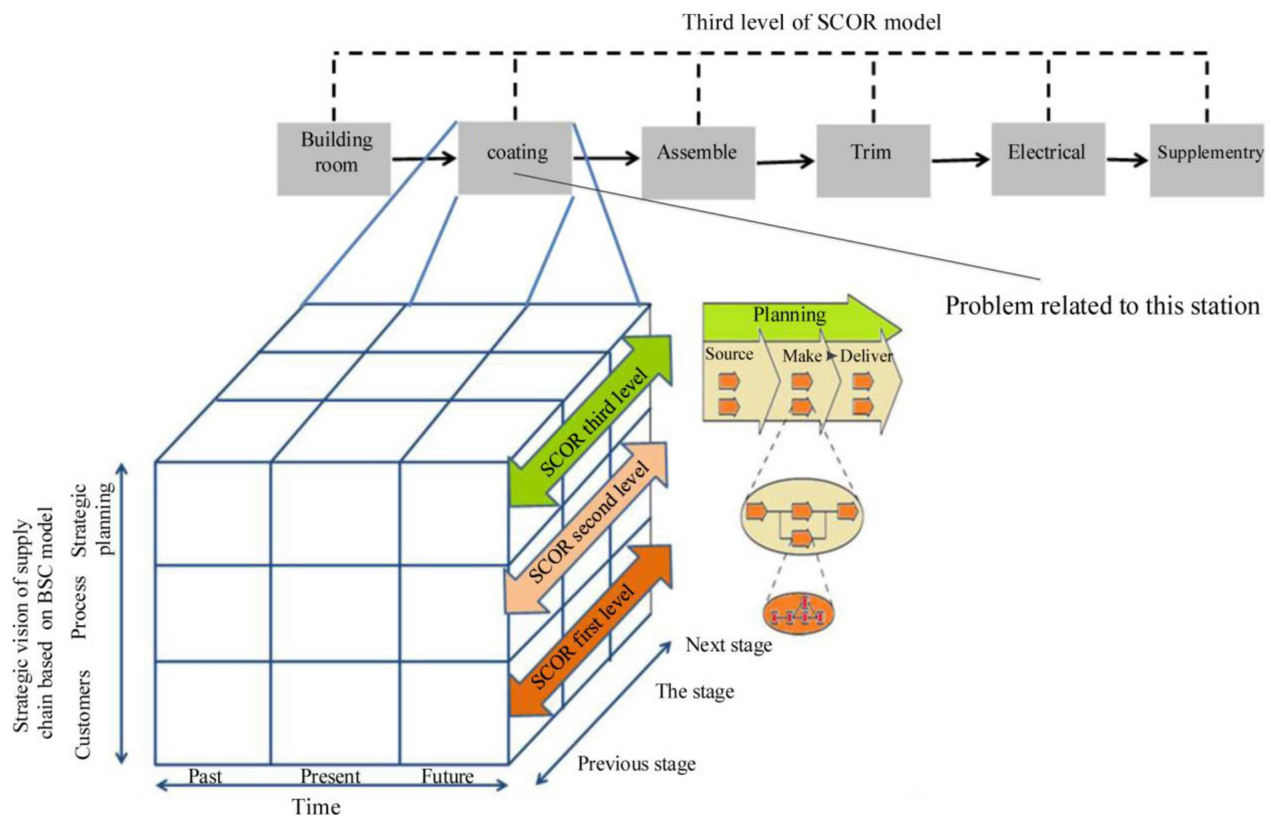

Figure 4. Analyzing the system operator based on the third level of SCOR model. 
Table 1. Components of the three-dimensional system operator.

\begin{tabular}{|c|c|c|c|c|}
\hline Z-axis & $\mathrm{X}$-axis (past) & $\mathrm{X}$-axis (present) & $\mathrm{X}$-axis (future) & $Y$-axis \\
\hline \multirow{3}{*}{ 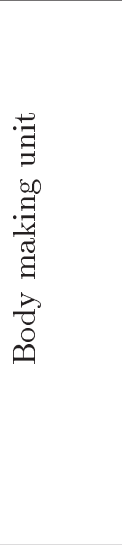 } & Production & $\begin{array}{l}\text { Increase innovation and } \\
\text { competitiveness, and reduce } \\
\text { the number of failures }\end{array}$ & $\begin{array}{l}\text { Enhance company branding } \\
\text { and increase productivity } \\
\text { through sustainable } \\
\text { management }\end{array}$ & $\begin{array}{l}\text { Strategic } \\
\text { planning }\end{array}$ \\
\hline & $\begin{array}{l}\text { The completion of the } \\
\text { main structure }\end{array}$ & $\begin{array}{l}\text { Make the completion of the } \\
\text { main frame semi-automatic }\end{array}$ & $\begin{array}{l}\text { Use automatic equipment } \\
\text { for frame construction }\end{array}$ & Process \\
\hline & $\begin{array}{l}\text { Strong focus on domestic } \\
\text { customers }\end{array}$ & $\begin{array}{l}\text { Pay more attention to the } \\
\text { demands of customers in } \\
\text { the design phase }\end{array}$ & $\begin{array}{l}\text { Manufacture in world class } \\
\text { and offer environmentally } \\
\text { friendly products }\end{array}$ & Customers \\
\hline \multirow{2}{*}{ 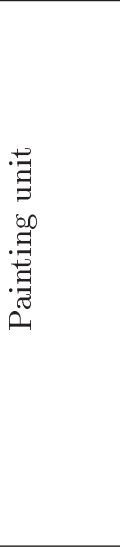 } & Production & $\begin{array}{l}\text { Increase innovation and } \\
\text { competitiveness, and reduce } \\
\text { the number of failures }\end{array}$ & $\begin{array}{l}\text { Enhance company branding } \\
\text { and increase productivity } \\
\text { through sustainable } \\
\text { management }\end{array}$ & $\begin{array}{l}\text { Strategic } \\
\text { planning }\end{array}$ \\
\hline & $\begin{array}{l}\text { Strong focus on domestic } \\
\text { customers }\end{array}$ & $\begin{array}{l}\text { Pay more attention to the } \\
\text { demands of customers in the } \\
\text { design phase }\end{array}$ & $\begin{array}{l}\text { Manufacture in world class } \\
\text { and offer environmentally } \\
\text { friendly products }\end{array}$ & Customers \\
\hline \multirow{3}{*}{ 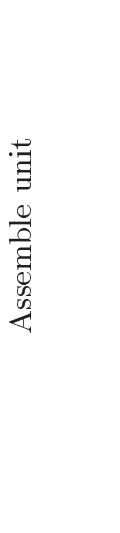 } & Production & $\begin{array}{l}\text { Increase innovation and } \\
\text { competitiveness, and reduce } \\
\text { the number of failures }\end{array}$ & $\begin{array}{l}\text { Enhance company branding } \\
\text { and increase productivity } \\
\text { through sustainable } \\
\text { management }\end{array}$ & $\begin{array}{l}\text { Strategic } \\
\text { planning }\end{array}$ \\
\hline & Powertrain assembly & $\begin{array}{l}\text { Automate the assembly } \\
\text { process }\end{array}$ & $\begin{array}{l}\text { Use high technology } \\
\text { for assembly }\end{array}$ & Process \\
\hline & $\begin{array}{l}\text { Strong focus on domestic } \\
\text { customers }\end{array}$ & $\begin{array}{l}\text { Pay more attention to the } \\
\text { demands of customers in the } \\
\text { design phase }\end{array}$ & $\begin{array}{l}\text { Manufacture in world class } \\
\text { and offer environmentally } \\
\text { friendly products }\end{array}$ & Customers \\
\hline
\end{tabular}

in the graph by the symbol (Pb1). In the next phase, the primary problem is studied from three viewpoints of customers, processes (production capacity), and the organizational structure and, in this regard, the following questions arise:

- What impacts this problem will have on production capacity $(\mathrm{Pb} 2)$ ?

- What impacts this problem will have on customer satisfaction $(\mathrm{Pb} 3)$ ?

- What potential effects this problem will have on the company's organizational structure $(\mathrm{Pb} 4)$ ?
Then, based on the proposed algorithm in this paper, the graph is drawn in a hierarchical structure (see Figure 5).

- Step 3: Building the network of conflicts from the network of problems. After completing the network of problems, we have to define at least one evaluation parameter and one control parameter for each problem and solution. In this case, supply chain performance indicators at different levels of SCOR model are used to define evaluation and control parameters (see Table 2). After determining the graph, a complete list of problems and solutions 


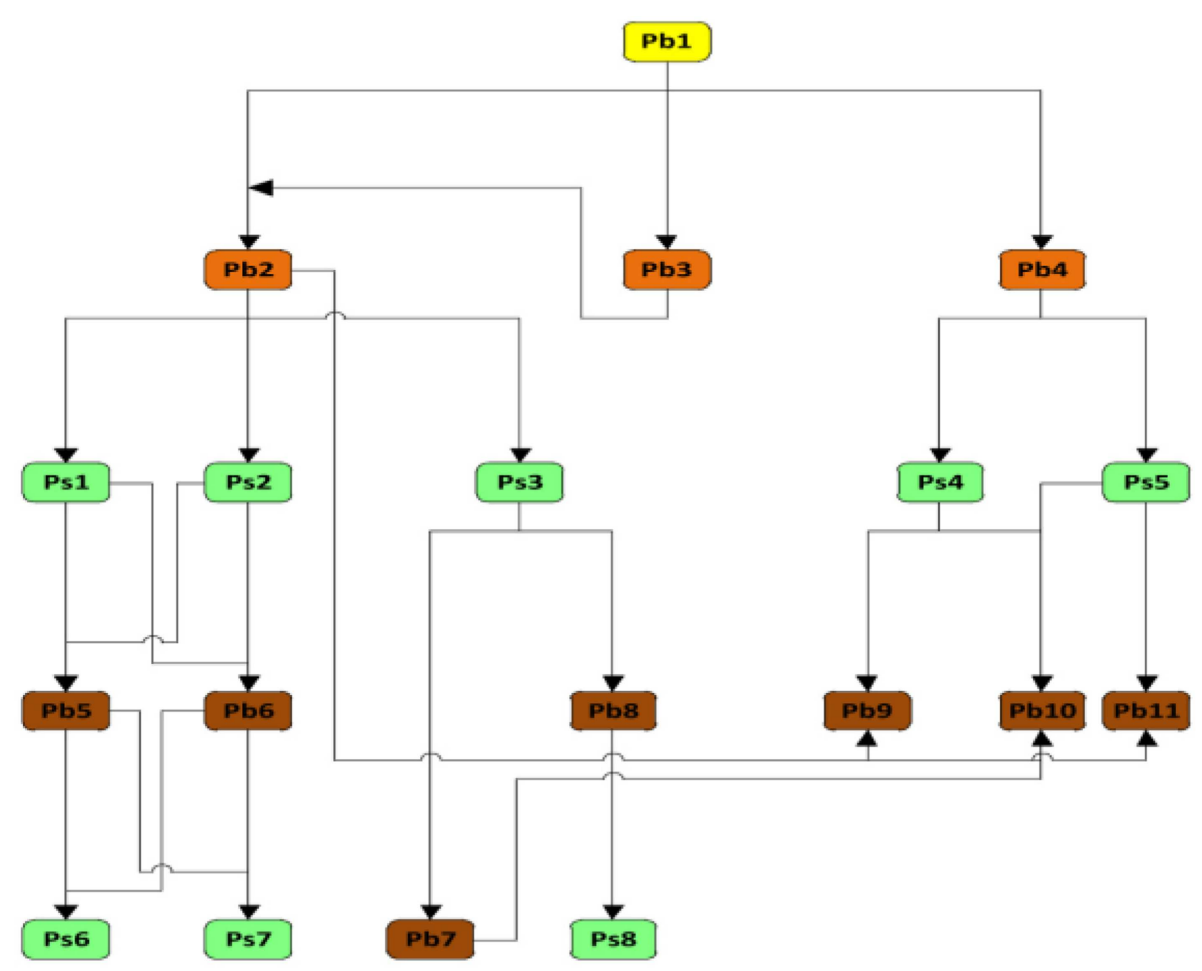

Figure 5. Flow network of replacement problems of old equipment of the coating line with semi-automatic equipment.

Table 2. Description of the problems and evaluation parameters.

\begin{tabular}{|c|c|}
\hline Description of problem $(\mathrm{Pb})$ & Evaluation parameters \\
\hline $\mathrm{Pb} 2:$ How to prevent delay in the production schedule? & EP2: Lost production capacity of line 3 \\
\hline Pb3: How to meet the needs of customers well? & EP3: The number of new contracts \\
\hline $\begin{array}{l}\mathrm{Pb} 4: \text { Do the current operators have sufficient knowledge } \\
\text { to work with new equipment? }\end{array}$ & EP4: Time \\
\hline Pb5: Production lines 1 and 2 work at full capacity. & EP5: Capacities of production lines 1 and 2 \\
\hline $\begin{array}{l}\text { Pb6: Disturbing other workers while installing new } \\
\text { equipment }\end{array}$ & EP6: Human resource costs \\
\hline $\mathrm{Pb7}$ : Increased cost of production & EP7: New machinery operator cost \\
\hline $\mathrm{Pb} 8$ : The time required for training new operators & $\begin{array}{l}\text { EP8: The time for educating and preparing } \\
\text { human resource }\end{array}$ \\
\hline $\begin{array}{l}\text { Pb9: The new operator has to be socialized and integrated } \\
\text { into the company culture }\end{array}$ & EP9: Socialization time \\
\hline Pb10: Speeding up the supply of parts & EP10: Lead time \\
\hline Pb11: Increasing the price of finished products & EP11: The price of final product \\
\hline Pb12: Changing human resource planning & EP12: Working time \\
\hline
\end{tabular}

is provided. Then, based on opinions of experts, one or more indicators are determined for every problem and solution. Table 3 includes control parameters that are determined for each of the solutions.

The potential conflicts existing between problems and solutions are determined through the defined evaluation and control parameters. For example, according to the partial solution suggested for $\mathrm{Pb} 2$, the capacities of production lines 1 and 2 are increased in order to compensate for the loss of capacity in line 3 . The senior management can solve this problem by changing the planned production capacities of lines 1 and 2 . If planned capacities of these lines are increased, on the one hand, the loss of capacity in line 3 is reduced as a positive effect; however, on the other hand, the 
Table 3. Description of partial solutions and control parameters.

\begin{tabular}{|c|c|}
\hline Partial Solution (PS) & Control parameters \\
\hline $\begin{array}{l}\text { PS1: Guaranteeing current obligations using the } \\
\text { capacities of lines } 1 \text { and } 2\end{array}$ & CP1: Production capacities of lines 1 and 2 \\
\hline $\begin{array}{l}\text { PS2: Installing new equipment at the next current } \\
\text { station }\end{array}$ & CP2: Replacement time \\
\hline $\begin{array}{l}\text { PS3: Recruiting new staff to work with new } \\
\text { equipment }\end{array}$ & CP3: New hired people \\
\hline $\begin{array}{l}\text { PS4: Training and preparing the current operator to } \\
\text { work with new machines }\end{array}$ & CP4: Educational background of operators \\
\hline $\begin{array}{l}\text { PS5: The replacement can be performed during the } \\
\text { plant maintenance period }\end{array}$ & CP5: Overhaul duration time \\
\hline $\begin{array}{l}\text { PS6: Installation of new equipment can be done at } \\
\text { the beginning of the new year when the quantity } \\
\text { of orders is low }\end{array}$ & CP6: Flexibility of production lines \\
\hline PS7: Adding night shifts to complete orders & $\begin{array}{l}\text { CP7: Flexibility of human resource and } \\
\text { supply chain management }\end{array}$ \\
\hline
\end{tabular}

production capacities of lines 1 and 2 will exceed the authorized amount planned. Therefore, the problem $\mathrm{Pb} 5$ emerges. In other words, by solving problem $\mathrm{Pb} 2$, problem $\mathrm{Pb} 5$ arises. The result of such analysis of parameters of other problems and partial solutions will form the initial structure of the network of conflicts. The network of conflicts for replacement equipment in the coating line is shown in Figure 6.

As shown in Figure 6, the network of conflicts is created and drawn based on the semantic relationships between elements, features, and values that were determined on the basis of ENV model. According to the graph, if CP1 adopts the amount of V1 (increased production capacity of lines 1 and 2), parameter EP2 (lost capacity of production line 3 ) is improved and the parameter EP5 is weakened; and if CP1 adopts the amount of V2 (decreased production capacity of lines 1 and 2), EP5 is improved and EP2 is weakened. Thus, there is a conflict between the parameters of EP2 and EP5. This is also true for other parameters. If any of these conflicts is analyzed separately, there is not any conflict, but when there is integration between the elements of the system, changing values of parameters (indices) for each of the system elements will lead to improvement or weakening of other elements of the system parameters.

\section{Conclusion}

Although collaboration can lead to substantial reciprocal advantages, activities often produce less than favorable consequences. Many of these deficiencies result from conflicts of supply chains. Therefore, if managers can find potential conflicts before their occurrence, they can resolve the problem and tactfully redesign the supply chain to avoid future problems. In this paper, we presented a knowledge based algorithm for carrying out this task and validated it in a supply chain in a make-to-order environment.

The proposed algorithm provided a systematic and structured decisional process that could be used as an innovative model for analyzing complex problems and acquiring experts' knowledge. Also, problem flow network kept the problem traceable through mapping the reasoning and semantic relationships between subproblems and solutions to find and formulate conflicts of the network of problems.

Additionally, the ENV model for representing the relationships between parameters was relatively simple to computerize and, thus, might be easily applied to large-scale systems.

Moreover, some managerial implications could be extracted as follows:

- The algorithm provided a condition to find and formulate all conflicts that might be encountered during the replacement period and, as a result, it helped in coordinating the activities to reduce the cost of equipment replacement by $45 \%$;

- By having a complete list of replacement related problems and conflicts, the consequences of decisions could be foreseen and a careful schedule for the replacement project could be made to efficiently use human resource and production lines. 


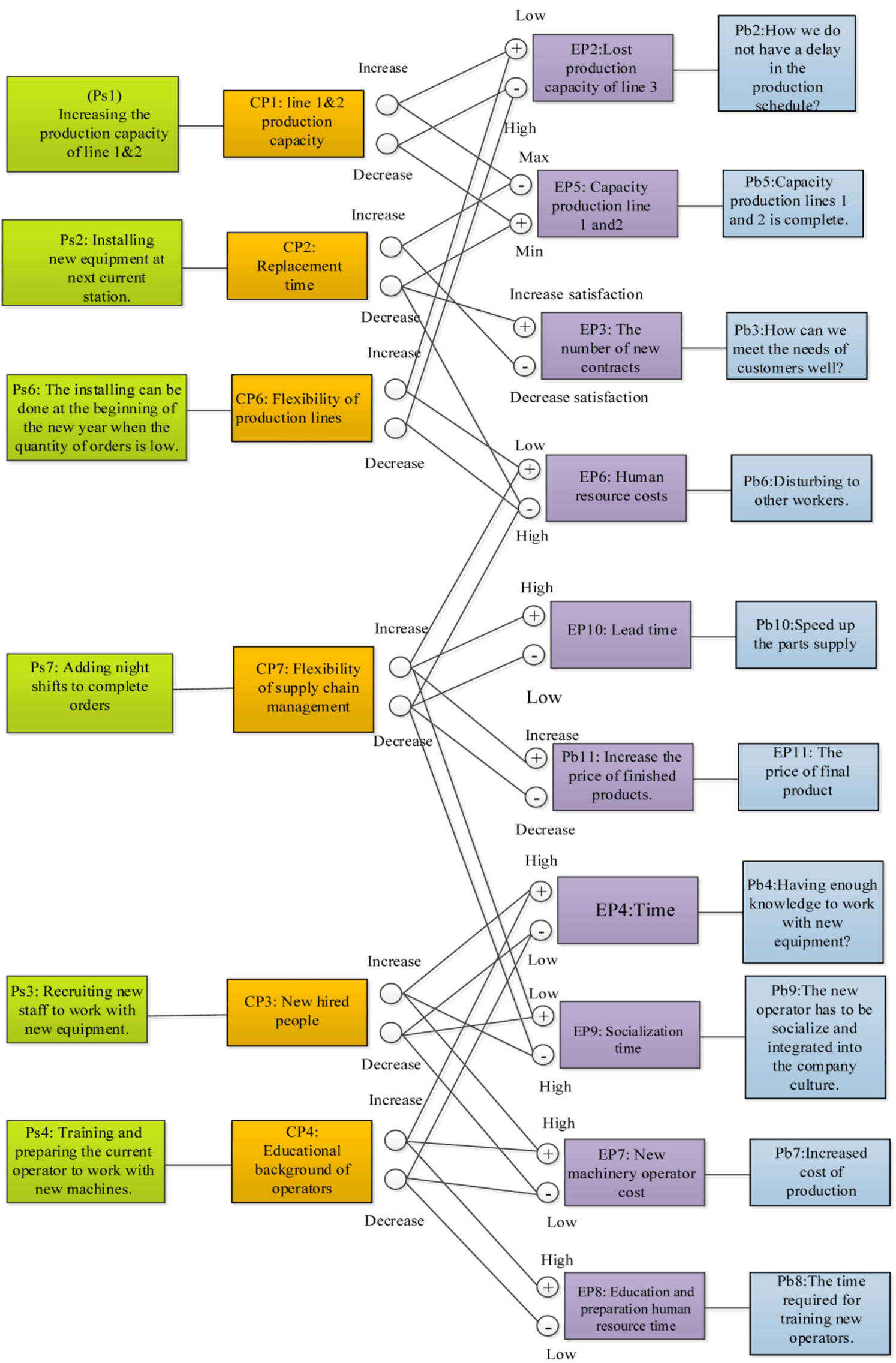

Figure 6. The network of conflicts for the bottleneck problem of line 3 . 
Future work in this area will include designing a fuzzy multi-criteria decision making system for analyzing and prioritizing conflicts as well as resolving the roots by a combination of TRIZ tools and supply chain conflict resolving strategies. A second area for future research includes developing a three-dimensional operator system as an innovative tool for analyzing and resolving supply chain problems.

\section{References}

1. Behzadi, G., O'Sullivan, J., Olsen, T., Scrimgeour, F., and Zhang, A. "Robust and resilient strategies for managing supply disruptions in an agribusiness supply chain", International Journal of Production Economics, 191, pp. 207-220 (2017).

2. Barutcu, S. and Dugan, H. "Supply chain-based conflict: A study from textile exporter's perspectives", Journal of Global Strategic Management, 42, pp. 231244 (2010).

3. Lam, P.K., Chin, K.S., and Pun F.T. "Managing conflict in collaborative new product development: a supplier perspective", International Journal of Quality \& Reliability Management, 24(9), pp. 891-907 (2007).

4. Vachon, S., Halley, A., and Beaulieu, M. "Aligning competitive priorities in the supply chain: The role of interactions with suppliers", International Journal of Operations \& Production Management, 29(4), pp. 322-340 (2009).

5. Ogunlana, S.O. and Mahato, B.K. "Conflict dynamics in a dam construction project: A case study", Built Environment Project and Asset Management, 1(2), pp. 1-21 (2011).

6. Alam, T. and Faridi, M.R. "Conflicts in supply chain management", VSRD-IJBMR, 1(10), pp. 648654 (2011).

7. Klibi, W. and Martel, A. "Modeling approaches for the design of resilient supply networks under disruptions", International Journal of Production Economics, 135(2), pp. 882-898 (2012).

8. Rice, J. and Caniato, F. "Building a secure and resilient supply chain", Supply Chain Management Review, 7(5), pp. 22-30 (2003).

9. Brockman, J.L. "Interpersonal conflict in construction: Cost, cause, and consequence", Journal of Construction Engineering and Management, 140(2) (2014). DOI: doi.org/10.1061/(ASCE)CO.1943-7862.0000805

10. Pyke, D. and Tang, C.S. "How to mitigate product safety risks proactively? Process, challenges and opportunities", International Journal of Logistics Research and Applications: A Leading Journal of Supply Chain Management, 13(4), pp. 243-256 (2010).

11. Hendricks, K.B. and Singhal, V.R. "The effect of demand-supply mismatches on firm risk", Production and Operations Management, 23, pp. 2137-2151 (2014).
12. Hendricks, K.B. and Singhal, V.R. "The effect of supply chain glitches on shareholder wealth", Journal of Operations Management, 21, pp. 501-522 (2003).

13. Hendricks, K.B. and Singhal, V.R. "An empirical analysis of the effect of supply chain disruptions on long run stock price performance and equity risk of the firm", Production and Operations Management, 14(1), pp. 35-52 (2005).

14. Hendricks, K.B. and Singhal, V.R. "The effect of supply chain disruptions on shareholder value", Total Quality Management, 19(7), pp. 777-791 (2008).

15. Lam, P.K. and Chin, K.S. "Identifying and prioritizing critical success factors for conflict management in collaborative new product development", Industrial Marketing Management, 34(8), pp. 761-772 (2005).

16. Felty, A. and Namjoshi, K. "Feature specification and automated conflict detection", ACM Transactions on Software Engineering and Methodology, 2(1), pp. 3-27 (2003).

17. Mitkus, S. and Mitkus, T. "Causes of conflicts in a construction industry: A communicational approach", Procedia-Social and Behavioral Sciences, 110, pp. 777786 (2014).

18. Acharya, N.K., Dai, L.Y., and Kim, J.K. "Critical construction conflicting factors identification using analytical hierarchy process", KSCE Journal of Civil Engineering, 10(3), pp. 165-174 (2006).

19. Hsieh, C., Wee, H., and Chen, A. "Resilient logistics to mitigate supply chain uncertainty: A case study of an automotive company", Scientia Iranica, 23(5), pp. 2287-2296 (2016).

20. John, F.R. and Prasad, P.S.S. "Supply chain conflict detection with colored petri nets", Journal of Advances in Management Research, 9(2), pp. 208-216 (2012).

21. He, S., Hipel, K.W., and Kilgour, D.M. "A hierarchical approach to study supply chain conflicts between Airbus and Boeing", IEEE International Conference on Systems, Man, and Cybernetics (SMC), San Diego, CA, pp. 1559-1564 (2014).

22. He, S., Hipel, K.W., and Kilgour, D.M. "A hierarchical graph model of a two-level carbon emission conflict in China", IEEE International Conference on Systems, Man, and Cybernetics (SMC), Budapest, pp. 34233428 (2016).

23. Alaei, S. and Setak, M. "Supply chain coordination via two-way cooperative advertising contract considering competing retailers", Scientia Iranica, 23(5), pp. 23302340 (2016).

24. Khomenko, N., De Guio, R., Lelait, L., and Kaikov, I. "A framework for OTSM-TRIZ based computer support to be used in complex problem management", International Journal of Computer Applications in Technology, 30(1), pp. 88-104 (2007). 
25. Cavallucci, D., Rousselot, F., and Zanni, C. "Initial situation analysis through problem graph", CIRP Journal of Manufacturing Science and Technology, 2(4), pp. 310-317 (2010).

26. Cavallucci, D. and Khomenko, N. "From TRIZ to OTSM-TRIZ: Addressing complexity challenges in inventive design", International Journal of Product Development, 4(1), pp. 4-21 (2007).

27. Yan, W., Liu, H., Zanni- Merk, C., and Cavallucci, D. "Ingenious TRIZ: An automatic ontology-based system for solving inventive problems", KnowledgeBased Systems, 75, pp. 52-65 (2015).

28. Baldussu, A., Becattini, N., and Cascini, G. "Network of contradictions analysis and structured identification of critical control parameters", Procedia Engineering, 9, pp. 3-17 (2011).

29. Chechurin, L. and Borgianni, Y. "Understanding TRIZ through the review of top cited publications", Computers in Industry, 82, pp. 119-134 (2016).

30. Cheng, J. and Sheu, J. "Inter-organizational relationships and strategy quality in green supply chains moderated by opportunistic behavior and dysfunctional conflict", Industrial Marketing Management, 41(4), pp. 563-572 (2012).

31. Ntabe, E.N., LeBel, L., Munson, A.D., and SantaEulalia, L.A. "A systematic literature review of the supply chain operations reference (SCOR) model application with special attention to environmental issues", International Journal of Production Economics, 169, pp. 310-332 (2015).

32. Cavallucci, D., Rousselot, F., and Zanni, C. "On contradiction clouds", Procedia Engineering, 9, pp. 368-378 (2011).

\section{Biographies}

Jafar Razmi is a Professor in the Department of Industrial Engineering at University of Tehran, Tehran, Iran. He teaches undergraduate and graduate courses in Industrial Engineering and Operations Management. He has published over 60 papers in peer-reviewed journals and published about 50 papers in conferences. He is in the editorial board of 4 journals and is currently the chief editor of Journal of Industrial Engineering published in Iran. His research interests include SCM, MCDM, production planning and control, lean manufacturing, and manufacturing measurement and evaluation.

Davoud Haghighi is currently a member of Young Researchers and Elite Club, Majlesi Branch, Islamic Azad University, Isfahan. He has published some papers in peer-reviewed journals and conferences. His research interests include forecasting, ANN, and supply chain management.

Reza Babazadeh is an Assistant Professor in the Faculty of Engineering at the University of Urmia, Urmia, Iran. He teaches undergraduate and graduate courses in Industrial Engineering, Supply Chain Management, Advanced Engineering Economy, and Probability and Statics. He has published over 20 papers in peer-reviewed journals, such as Omega and Journal of Cleaner Production, and conferences. His research interests include supply chain management, risk management, production planning under uncertainty, and forecasting. 